\title{
Saúde eeconomia verde: desafios para o desenvolvimento sustentável e erradicação da pobreza
}

\author{
Health and the green economy: challenges \\ for sustainable development and the eradication of poverty
}

Edmundo Gallo ${ }^{1}$

Andréia Faraoni Freitas Setti ${ }^{2}$

Danielly de Paiva M agalhães ${ }^{2}$

Jorge M esquita Huet $M$ achado $^{3}$

Daniel Forsin Buss ${ }^{4}$

Francisco de Abreu Franco N etto ${ }^{5}$

Paulo M archiori Buss ${ }^{2}$

${ }^{1}$ Escola N acional de Saúde Pública Sérgio Arouca,

Fiocruz. Av. Brasil 4.365,

M anguinhos. 21040-360

Rio deJaneiro RJ.

gallo@fiocruz.br

${ }^{2}$ Centro de Relações

Internacionais em Saúde,

Fiocruz

${ }^{3}$ Programa dePromoção da

SaúdeAmbienteeTrabalho,

Diretoria Regional de

Brasília, Fiocruz

${ }^{4}$ Laboratório deAvaliação e

Promoção da Saúde

Ambiental. Instituto

Oswaldo Cruz, Fiocruz

${ }^{5}$ Vice-Presidência de

Ambiente, Atenção e

Promoção da Saúde, Fiocruz
Abstract In a scenario where ecosystemic services are being eroded and there is high social inequity, a new model of development is necessary, namely one capable of promoting social development with a reduction of its ecological footprint. The 'Green Economy' model is one of the proposed models. This paper seeks to analyze the environmental, social and individual impacts on human health in the context of a 'brown economy', and discusses the contributions of a green economy on the promotion of equity and health. The assumption is that economic development and environmental sustainability are not incompatible and both contribute to the eradication of poverty. The transition to a sustainableeconomy depends on political decisions, and transcends technological developments. Aboveall, it should instigatenew models of production, consumption and social organization, which promote socio-environmental justice, encouraging social participation and democratic forms of governance to define a solid agenda for the implementation of sustainable development and mechanisms to implement them at all levels. Key words Productive implementation of health, Sustainable development, Capitalism, Brown economy, Rio+20, Socio-environmental justice
Resumo Em um cenário onde os serviços ecossistêmicos vão sendo perdidos e há graves iniquidades sociais énecessário um novo modelo de crescimento capaz de promover o desenvolvimento social com a redução da pegada ecológica. A 'economia verde' éum dos model os propostos. Este trabalho analisa os impactos ambientais, sociais e individuais da economia marrom na saúde humana eaborda as contribuições da economia verde para a promoção da equidadee saúde. Assume que o desenvolvimento econômico ea sustentabilidade ambiental não são incompatíveis e contribuem para o combateà pobreza. A transição para uma economia sustentável depende de deci sões políticas e vai além do desenvolvimento de tecnologias, devendo implantar um novo modo de produção, consumo e organização social que promova a justiça socioambiental, incentivando a participação social e as formas democráticas de governança para definir uma agenda concreta de implementação de objetivos para o desenvolvimento sustentável edemecanismos capazes deimplementá-los em todos os níveis.

Palavras-chave Complexo produtivo da saúde, Desenvolvimento sustentável, Capitalismo, Economia marrom, Rio+20, Justiça socioambiental 


\section{Introdução}

A década de 1970, sobretudo a partir da crise do petróleo em 1973 e da consequente onda inflacionária que a acompanhou, foi marcada como um período de transição do modelo econômico centrado no Estado de Bem-estar Social para um modelo de Estado neoliberal, que privilegiou o equilíbrio fiscal e monetário dos países, reduzindo sistemas de proteção social e atribuindo ao mercado a possibilidade de realização das necessidades sociais em detrimento do papel dos estados nacionais.

Como consequência deste modelo e de suas políticas, houve uma piora sensível nas condições de vida das populações, especialmente nos países mais pobres e em desenvolvimento, mas também impactando os países centrais. Esse período se estendeu até o final da década de 1990 quando começaram a ser retomados mecanismos de regulamentação econômica e proteção social.

N este contexto, a agenda dos organismos internacionais, da década de 2000 voltou-se para o social, gerando um "ciclo social" 1,2 representado por diversas conferências da ONU, especialmentea Conferência de Direitos Humanos de 1993, a Conferência Mundial sobre Mulheres de 1995, a Conferência Internacional sobreo Financiamento ao Desenvolvimento de 2002, a Conferência de Durban de 2002 e mais recentemente a Conferência M undial deD eterminantes Sociais da Saúde, em 2011.

Essa agen da permitiu que a saúde tivesse papel proeminente, o que se refletiu na definição dos ODM . Dos oito objetivos, três são especificamente da área da saúde, e os outros cinco diretamente relacionados a ela.

0 conceito desustentabilidadeentrou em cena principalmente a partir do Relatório M eadows, conhecido como Relatório do Clube de Roma ${ }^{3}$, queidentificou como principais ameaças à sobrevivência do planeta a industrialização acelerada, 0 rápido crescimento demográfico, a escassez de alimentos, o esgotamento de recursos não renováveis e a deterioração do meio ambiente.

Ainda que criticado, o relatório épioneiro em identificar desafios importantes neste campo, influenciando de maneira decisiva o debate na Conferência das Nações Unidas sobre o M eio Ambiente Humano (Estocolmo, 1972), quereuniu a comunidade internacional para discutir 0 meio ambienteglobal eas necessidades de desenvolvimento e que produziu um documento que sinalizava a necessidade de se criar um processo de gestão planetária dos problemas ambientais que culminou, logo após, na criação do Programa das $N$ ações Unidas para o M eio Ambiente (PNUMA).

Era preciso redefinir o próprio conceito de desenvolvimento, tantas e tão complexas eram as questões envolvidas. A Comissão Mundial para o M eio Ambiente e Desenvolvimento, criada em 1987, produz então o relatório “O ur Common Future" - Nosso Futuro Comum - mais conhecido como Relatório Brundtland, nele formulando o concei to 'clássico' de desenvolvimento sustentável: "Desenvolvimento que atende às necessidades do presente sem comprometer a possibilidade das futuras gerações de atender às suas próprias", concebido como processo de transformação no qual a exploração dos recursos naturais, a direção dos investimentos, a orientação do desenvolvimento tecnológico ea mudança institucional devem se harmonizar e re forçar o potencial presenteefuturo a fim deatender às necessidades e aspirações humanas ${ }^{4,5}$.

Os efeitos desse modelo de desenvolvimento refletiram-se no aquecimento global, no buraco na camada de ozônio, na poluição ena diminuição da quantidade de água potável, na desertificação, na contaminação do solo, na poluição do ar, na escassez de recursos naturais, na extinção de espécies, na perda da biodiversidade, entre outros, o que apontava para a insustentabilidade deste modelo, ameaçando a vida no planeta.

Buscando responder a esse quadro, houve um conjunto de iniciativas da ONU, como a Eco 92 - Cúpula da Terra, Johannesburg 2002 - Rio + 10, a Conferência Nacional de Saúde Ambiental, a 10ํㅡㄹ Conferência Internacional de Saúde Urbana, e as diversas COP - Painel de Alto Nível da ONU para as Mudanças Climáticas. Esse processo consolidou a importância da agenda da sustentabilidade para a sobrevivência do planeta, o que hoje a coloca como agenda prioritária do ponto de vista global.

0 The Lancet, em recente editorial ${ }^{6}$, discute essa transiçãa de agendas, e concorda que, nesta década, o destaque será da agenda da sustentabilidade. Porém, longe de isto significar perda de espaço para a saúde, coloca para o setor o desafio de inserir-se em uma agenda intersetorial capaz de impulsionar o enfrentamento dos determinantes sociais da saúde, o que dialoga estreitamente com o desenvolvimento sustentável.

Para além disso, énecessário atualizar a agenda dos ODM, ainda incompleta, que representa o ciclo social e articulá-la aos Objetivos de Desenvolvimento Sustentável (ODG), inserindo-se assim no ciclo da sustentabilidade, sendo um dos seus três pilares. 
A agenda dos determinantes sociais da saúde, reafirmada recentemente na Conferência Mundial deD eterminantes Sociais da Saúde, 2011, é a que permite um diálogo direto e imediato com a agenda da sustentabilidade, convergindo para a Rio + 20 onde se espera que haja a reafirmação de princípios e a definição de estratégias concretas para a sua implementação.

Nos vinte anos que se passaram desde a Eco 92, foi fundamental a institucionalização e o grau de consenso alcançado pelo desenvolvimento sustentável enquanto novo paradigma e princípio estruturante para 0 desenvolvimento, permitindo 0 avanço na criação de tecnologias, elaboração de indicadores e no envolvimento governamental, social e comunitário7.

Ainda que haja dimensões conceituais a serem esclarecidas, como o conceito de economia verde, 0 aspecto mais criticado é o da baixa implementação de medidas concretas capazes de enfrentar os principais desafios relacionadas à efetividade de políticas, pesquisas e outras estratégias que articulem os três pilares do desenvolvimento sustentável: desenvolvimento econômico, equidade social e proteção ambiental ${ }^{5,8-11}$.

A Rio+20 tem como Agendas centrais a Economia Verde e a Governança para o Desenvolvimento Sustentável ${ }^{3}$. Ainda que aparentemente sejam agendas consensuais, seus conceitos e sua implementação prática é controversa. Há desde posições que apontam para o "esverdeamento do capitalismo"12, até as que as identificam como o caminho para a transformação para um mundo mais solidário. Todas, entretanto, destacam a importância de que se aprofundem o debate sobre o conteúdo e as estratégias destas Agendas.

A saúde tem procurado intervir mais decisivamentenessas A gendas, desenvolvendo a teoria da determinação social da saúde e seus desdobramentos. Três áreas da saúde voltaram-se, de modo mais especifico, para a compreensão e a ação sobre as interfaces entre meio ambiente, desenvolvimento sustentável (produção) e saúde: promoção da saúde, saúde ambiental e complexo produtivo da saúde tendo em comum o grande potencial para combater a pobreza, por meio da inclusão social e da proteção ao meio ambiente baseado em uma governança democrática e participativa.

Este trabalho tem como objetivo trazer os princípios da Economia Verde e suas contribuições para a promoção da equidade, erradicação da pobreza e no setor da saúde, salientando sua urgência para a mitigação dos impactos causados pelo modelo de desenvolvimento econômico atual (economia marrom), e, finalmente, desta- cando os desafios teórico- práticos para o desenvolvimento sustentável ea saúde, com a perspectiva de oferecer subsídios que auxiliem na criação de agendas mais sustentáveis.

\section{Princípios da Economia verde}

A pegada ecológica da humanidade dobrou desde 1966 e, em 2007, a biocapacidade utilizada do planeta foi $50 \%$ maior que sua renovação. 0 modo hegemônico de produção e consumo, desdea década de 1980, tem gerado uma dívida ecológica importante. Continuando com esse padrão econômico, até 2030, a humanidade precisará da biocapacidade de dois planetas Terra para absorver os resíduos de $\mathrm{CO} 2$ e manter o consumo de recursos naturais ${ }^{13}$.

0 relatório do PNUMA ${ }^{14}$ demonstra que a transição para uma economia verde de baixo carbono e al ta eficiência de recursos seria possível se fossem investidos 2\% do PIB global por ano em dez setores estratégicos, que seriam: construção civil; energia; pesca; silvicultura; indústria; turismo; transporte; resíduos e reciclagem; água e saneamento básico - sendo o maior investimento dessemontanteem energia, $30 \%$, seguido de $16 \%$ em transporte.

0 documento assume que 0 desenvolvimento econômico deve ser atrelado à melhoria do índice de desenvolvimento humano, reduzindo ou mantendo sua pegada ecológica baixa. N estesentido, a economia verde preconiza pel a valorização eincentivo em atividades com baixo teor deemissão de carbono, racionalização dos recursos, integração social, proteção e reforço da biodiversidadee dosserviços fornecidos pelos ecossistemas.

$\mathrm{Na}$ transição para essa nova economia, muitos empregos se extinguiriam, porém novos, denominados verdes, seriam criados, onde o trabalhador teria liberdade, remuneração equitativa, segurança no local de trabal ho e proteção social. Para isso, os governos deveriam promover o incentivo adequado utilizando instrumentos econômicos, normas, inovação e difusão tecnológica, políticas distributivas e voluntárias e iniciativas que possam ajudar a canalizar investimentos - públicos e privados - para setores específicos eaumentar sua eficácia e equidade.

Isto implica em alterar a política fiscal, reformar e reduzir os subsídios a empreendimentos prejudiciais ao ambiente, redirecionar os investimentos para setores verdes-chave, que utilizem recursos naturais e energia em menor quantidadeou deforma eficienteequesejam socialmente inclusivos. Isto eliminaria indústrias marrons que em grande medida existem devido a subsídios ${ }^{14}$. 
As metodologias de políticas públicas para uma economia verde deverão ser diferentes em cada país, levando-se em consideração suas condições socioeconômicas einstitucionais específicas, seus recursos naturais e pontos de pressão ambiental ${ }^{15}$. Teoricamente, todos os países teriam ganhos econômicos diretos ao fazer a transição para uma economia verde, por meio de maior produtividade, otimização de recursos, ampliação de empregos a partir da inovação e do surgimento de mercados e atividades verdes. Se forem alcançados esses objetivos, a pegada ecológica global sobre a taxa de biocapacidade poderia diminuir para menos de 1,2 gha até 2050, reduzindo em $33 \%$ as emissões de dióxido decarbono elimitando assim o aquecimento global ao limiar de dois graus Celsius ${ }^{16}$. Os benefícios de uma economia verde resultariam em maior saúde e bem-estar com menor poluição.

\section{Economia Verde}

e a Erradicação da Pobreza:

agenda dos organismos internacionais

para o desenvolvimento sustentável

Em todas as partes do mundo, a pobreza e as precárias condições de vida permanecem sendo uma das maiores causas das doenças. Apesar dos índices de mortalidade por doenças infecciosas terem caído, aumentou o número de doenças ligadas às formas de vida e às alterações nas dietas. A desnutrição crônica ou a fometornam muitas pessoas vulneráveis ao adoecimento e às mortes precoces. Um exemplo disso são os índices de mortalidade infantil, que vêm declinando, mas não na mesma velocidade para todas as classes sociais ${ }^{17}$.

A Comissão Econômica para América Latina e Caribe (CEPAL) estimou que 10,3\% da população latino-americana, em 2005, vivia na extrema pobreza, eque $12,7 \%$ da população era composta por indigentes, em 2007. Considera-se em extrema pobreza as pessoas que não satisfazem três ou mais necessidades básicas ${ }^{18}$.

As atuais tendências projetadas para a agricultura, caso persista o modelo atual, são menos eficientes do queas da economia verde. Por exemplo, os investimentos em agricultura verde conduziriam, ao longo do tempo, ao aumento da qualidade do solo e ao crescimento da produção global das principaisculturas, representando uma produção 10\% acima do projetado com as estratégias atuais de investimento. 0 aumento da eficiência na agricultura e nos setores industrial e urbano reduzi ria a demanda de água em cerca de um quinto até 2050 em comparação com as tendências projetadas, reduzindo a pressão sobre 0 lençol freático e a água superficial, tanto a curto quanto a longo prazo, impactando positivamente eixos importantes das políticas de erradicação da fome e da miséria ${ }^{14}$.

Assim, sob um panorama de economia verde inclusiva, o crescimento econômico e a sustentabilidade ambiental não seriam incompatíveis e contribuiriam para o combate à pobreza, uma vez que os serviços ecossistêmi cos são componentes das vidas de comunidades e proporcionam uma rede de segurança contra desastres naturais e disponibilidade de serviços essenciais, como por exemplo a água.

A economia verde pode estar alinhada à promoção e à defesa dos Objetivos de Desenvolvimento do Milênio que tem, entre outras, a meta dereduzir pela metadeo número de pessoas com fome e sem acesso a água potável. 0 relatório "A economia dosecossistemas e da biodiversidade"19 analisa a correlação entre os serviços ecossistê micos e os ODM (Quadro 1).

O Quadro apresenta relação indireta entreos serviços ecossistêmicos e todos os ODM à exceção do ODM 1 - Erradicar a pobreza extrema ea fome, que apresentou "relações fortes e diretas: a intervenção precisa ser receptiva aos serviços ecossistêmicos, à biodiversidade e à resiliência dos ecossistemas cultivados". O ODM 7 - Qualidade de vida e respeito ao meio ambiente não écitado, provavelmente por ser transversal aos demais.

0 mundo avança nessa direção, apesar da recessão econômica mundial, mas demonstra fragilidade nas áreas vitais, tais como a melhoria da saúde materna e acesso a um saneamento de qualidade, conforme publicado no Relatório de Acompanhamento dos ODM ${ }^{20}$ que também recomenda a criação de empregos, a promoção do crescimento econômico, a segurança alimentar, a promoção das energias limpas e o reforço das parcerias entre os países ricos e pobres, para ajudar as populações mais vulneráveis do mundo. 0 relatório revela que, nas duasúltimas décadas, o mundo conseguiu reduzir a percentagem de pessoas que vivem na pobreza extrema, baixou de $46 \%$ em 1990, para $27 \%$, em 2005, com previsão para atingir $15 \%$ até $2015^{20}$.

O Brasil tem se apoiado em políticas sociais, de alcance nacional, com o objetivo de reduzir a pobreza e as desigualdades garantindo os direitos dos cidadãos, como é o caso do conjunto de ações para o combate à fome e à pobreza, que hoje se configura no Plano Brasil sem Miséria. Somadas a outros fatores, como 0 crescimento da economia e a geração de empregos, elas já possibilitaram não apenas eliminar pela metade a proporção da população pobre no pais - M eta do primeiro ODM - como também cumprir a 
Quadro 1. Serviços ecossistêmicos e os Objetivos de Desenvolvimento do Milênio (ODM): Relações e trade- offs

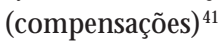

\begin{tabular}{|c|c|c|c|c|}
\hline $\begin{array}{c}\text { Serviços } \\
\text { Ecossistêmicos }\end{array}$ & $\begin{array}{l}\text { Relação com } \\
\text { ODM }\end{array}$ & Relações com as metas & Resultado conflitante & Avaliação \\
\hline $\begin{array}{l}\text { Serviços de } \\
\text { Fornecimento e } \\
\text { Regulação }\end{array}$ & $\begin{array}{l}\text { ODM 1: } \\
\text { Erradicar } \\
\text { pobreza } \\
\text { extrema e } \\
\text { fome }\end{array}$ & $\begin{array}{l}\text { Fornecimento diário de água, } \\
\text { madeira e alimentação } \\
\text { estabilizado: isso influencia o } \\
\text { padrão material mínimo na vida } \\
\text { dos pobres, aliviando a pobreza e } \\
\text { a fome. }\end{array}$ & $\begin{array}{l}\text { M aiores conflitos pela } \\
\text { água, exploração de } \\
\text { recursos do solo, } \\
\text { costeiros e marinhos e } \\
\text { a resiliência da agrobio- } \\
\text { diversidade poderiam } \\
\text { ser trade-offs }\end{array}$ & $\begin{array}{l}\text { Relações fortes e } \\
\text { diretas: a intervenção } \\
\text { precisa ser receptiva aos } \\
\text { serviços ecossistêmicos, } \\
\text { à biodiversidade eà } \\
\text { resiliência dos } \\
\text { ecossistemas cultivados }\end{array}$ \\
\hline $\begin{array}{l}\text { Serviços de áreas } \\
\text { úmidas e florestas }\end{array}$ & $\begin{array}{l}\text { ODM 3: } \\
\text { Promover } \\
\text { igualdade } \\
\text { entre os } \\
\text { gêneros e } \\
\text { capacitar } \\
\text { mulheres }\end{array}$ & $\begin{array}{l}\text { M adeira e água: proximidade e } \\
\text { disponibilidadeadequadas } \\
\text { ajudariam alcançar } \\
\text { igualdadeentre os gêneros por } \\
\text { reduzir essa carga que recai } \\
\text { principalmente nas mulheres }\end{array}$ & $\begin{array}{l}\text { Poderia haver maior ex- } \\
\text { tração de água subterrâ- } \\
\text { nea. O fortalecimento } \\
\text { de direitos sobre a terra } \\
\text { para as mulheres } \\
\text { poderia, no entanto, } \\
\text { garantir enormemente } \\
\text { a prevenção da perda da } \\
\text { biodiversidade }\end{array}$ & Relação indireta \\
\hline $\begin{array}{l}\text { Serviços de for- } \\
\text { necimento (plantas } \\
\text { medicinais) e } \\
\text { regulação (água) }\end{array}$ & $\begin{array}{l}\text { ODM 5: } \\
\text { Aprimorar a } \\
\text { saúde materna }\end{array}$ & $\begin{array}{l}\text { M elhor disponibilidade de água } \\
\text { potável e serviços médicos } \\
\text { tradicionais criariam condições } \\
\text { viáveis }\end{array}$ & & Relação indireta \\
\hline $\begin{array}{l}\text { Serviços de } \\
\text { fornecimento e } \\
\text { regulação }\end{array}$ & $\begin{array}{l}\text { ODM 6: } \\
\text { Combater } \\
\text { HIV/AIDS, } \\
\text { malária e } \\
\text { outras } \\
\text { doenças }\end{array}$ & $\begin{array}{l}\text { Isto seria facilitado } \\
\text { aumentando-se a disponibilidade } \\
\text { de água potável }\end{array}$ & & Relação indireta \\
\hline $\begin{array}{l}\text { Serviços de } \\
\text { fornecimento }\end{array}$ & $\begin{array}{l}\text { ODM 8: } \\
\text { Desenvolver } \\
\text { uma Parceria } \\
\text { Global para } 0 \\
\text { Desenvolvimento }\end{array}$ & $\begin{array}{l}\text { Práticas de troca justas e } \\
\text { igualitárias e uma ordem } \\
\text { econômica global saudável } \\
\text { refletiriam o custo real de } \\
\text { exportação/importação na } \\
\text { perspectiva dos serviços } \\
\text { ambientais }\end{array}$ & & Relação indireta \\
\hline $\begin{array}{l}\text { Serviços de } \\
\text { fornecimento e } \\
\text { regulação }\end{array}$ & $\begin{array}{l}\text { ODM 4: } \\
\text { Reduzir } \\
\text { mortalidade } \\
\text { infantil }\end{array}$ & $\begin{array}{l}\text { Criando condições facilitadoras, } \\
\text { por exemplo por meio de água } \\
\text { potável }\end{array}$ & & Relação indireta \\
\hline $\begin{array}{l}\text { Serviços de } \\
\text { fornecimento e } \\
\text { regulação }\end{array}$ & $\begin{array}{l}\text { ODM 2: } \\
\text { Alcançar } \\
\text { educação } \\
\text { primária } \\
\text { universal }\end{array}$ & $\begin{array}{l}\text { Fornecimento de serviços pode } \\
\text { ser afetado pela expansão de } \\
\text { infraestrutura para a educação } \\
\text { (escolas e estradas) }\end{array}$ & & $\begin{array}{l}\text { Relação fraca ou pouco } \\
\text { clara }\end{array}$ \\
\hline
\end{tabular}

mais ousada, assumida voluntariamenteem 2005, de reduzir essa proporção para um quarto da população total ${ }^{21}$.
O Plano Brasil sem M iséria é dirigido para 16 milhões de pessoas que ainda permanecem na pobreza extrema, que não conseguiram se ins- 
crever em programas sociais como o Bolsa Família, muito menos ter acesso a serviços essenciais como água, luz, educação, saúde e moradia. A partir do M apa da Pobreza e do M apa Nacional de 0 portunidades, o governo brasileiro de senvolveu uma estratégia, chamada "Busca Ativa", que identifica as pessoas nessas condições, realizam o seu cadastro nos programas sociais e buscam identificar os meios mais eficientes para a melhoria da sua qualidade de vida22.

O Programa Bolsa Verde faz parte do Plano Brasil sem M iséria, que beneficia famílias da Região N orte em situação de pobreza extrema que vivem em áreas de preservação ambiental, quea cada três meses receberão a bolsa por serviços ambientais de conservação das áreas onde vivem e trabal ham e qualificação em manejo florestal e educação ambiental. Até 2014, o Governo Federal pretende atender 72 mil famílias de pequenos produtores e comunidades tradicionais que vivem em área de preservação e assentamentos de reforma agrária que contêm recursos florestais importantes ${ }^{23}$.

Esse contexto indica que a implementação de políticas sustentáveis tem potencial para enfrentar a pobreza, promover a equidade, melhorar a qualidade de vida e a sustentabilidade do planeta. A Rio+20 deverá enfrentar uma série de desafios nesse sentido.

\section{Economia verde na saúde}

A Avaliação Ecossistêmica do Milênio ${ }^{24}$ reconhece que o bem estar humano depende de determinantes múltiplos, sendo os serviços ecossistêmicos indispensáveis à saúde das pessoas, e preconiza como requisitos mínimos para uma boa qualidade de vida: alimento, moradia, ar limpo, acesso à água potável e resiliência ao clima.

Para a Comissão N acional sobre os Determinantes Sociais da Saúde (CNDSS), os DSS são os fatores sociais, econômicos, culturais, étnicos/raciais, psicológicos e comportamentais que influenciam a ocorrência de problemas desaúdeeseus fatores de risco na população. Ascondições socioeconômicas, culturais e ambientais são concebidas como fatores macro-determinantes da saúde. Assim, o processo saúde-doença reflete as alterações territoriais, geográficas, demográficas produtivas e culturais que impactam o lugar de vida 25 .

J untamente com a redução dos gastos dedicados a saúde, a O PAS ${ }^{26}$ já reconhece que os efeitos das mudanças climáticas estão associados ao ressurgimento, na América Latina e no Caribe, de epidemias que estavam sob controle. A poluição ambiental pode levar a diversas complicações à saúde individual e pública, desde intoxicações químicas, cânceres, malformações congênitas, doenças neurológicas, imunológicas e respiratórias até redução ao acesso à alimentação e à água, vitais para a saúde humana.

I mpactos do modelo de desenvolvimento econômico atual na saúde

A mudança do atual modelo de desenvolvimento para o sustentável éjustificado, de modo imediato, pelas al terações catastróficas que aquele pode causar tanto para a economia, quanto para o ambiente e para a saúde.

0 clima, p.e., éum determinante da distribuição devetores e agentes patogênicos. 0 aumento da incidência-prevalência de doenças como malária, dengue, febre amarela, hantavirose, entre outras, tem sido associadas às mudanças climáticas $^{27}$. As alterações extremas detemperaturatambém irão contribuir para o aumento da poluição do ar e da água, escassez de alimentos e elevação dos níveis de ozônio, o que agrava as doenças cardiovasculares e respiratóriasintensificando alergias a pólen e outros alergênicos ${ }^{28}$.

A elevação das temperaturas também altera os regimes de precipitação e poderá prejudicar a produção de alimentos em muitas das regiões mais pobres, o que aumentará a prevalência de desnutrição e subnutrição, que atualmente resulta em 3,5 milhões de mortes a cada ano ${ }^{29}$. Ademais, em algumas regiões do mundo numerosas populações serão deslocadas pelo aumento do nível do mar ou serão seriamente afetadas por inundações, secas e fome e diminuição de terras apropriadas para a agricultura ${ }^{30,31}$.

Outros impactos ambientais do desenvolvimento econômico afetam indiretamentea saúde. Modificações do habitat, conversão de terras e desmatamento para criação de estradas e agricultura, alteram as condições ecológicas e podem levar à extinção de espécies. A perda da biodiversidade afeta os serviços do ecossistema, como a captura eficiente da energia da luz solar, a filtragem e a depuração de poluentes entre outros. A diversidade de espécies também éimportante na ecologia das doenças infecciosas, particularmente zoonoses transmitidas por vetores. A alta diversidade deespécies de hospedeirosvertebrados pode desempenhar um papel benéfico por impedir o domínio de determinadas espécies que atuam como reservatórios principais do patógeno, e, portanto, podem diminuir e/ou "diluir" o risco da doença32.

A construção de usinas hidrelétricas e barragens em geral, gera modificações ambientais cri- 
ando condições propícias ao estabelecimento de vetores, como os quetransmitem a esquistossomose, a malária e a febre amarela - doenças endêmicas mundialmente importantes, associadas a ambientes impactados s $^{33,34}$. Ainda assim, a realização desses empreen dimentos ocorre sem planos consistentes de mitigação daquel as doenças, ou até mesmo um incremento no serviço de saúde local para atendimento das mesmas.

A falta de tratamento adequado de efluentes domésticos e industriais e a lixiviação de áreas agrícolas permitem o lançamento de parasitos, bactérias, vírus e de substâncias tóxicas, genotóxicas, teratogênicas e carcinogênicas nos corpos hídricos. A água insalubre e a falta de condições de saneamento básico e higiene foram responsáveis por 1,9 milhões de mortes em $2004^{35}$. Os tratamentos de água convencionais são incapazes de retirar certas substâncias (disruptores endócrinos, antibióticos e cianotoxinas) da água para consumo humano. Muitas destas substâncias são persistentes no meio ambiente, acumulando-se no solo e no sedimento de rios sendo facilmente transportadas a longas distâncias. D epositam-se ao longo da cadeia trófica, representando um sé rio risco à segurança alimentar e nutricional. Os disruptores endócrinos causam também declínio da função do sistema imunológico, aumentando a propensão às doenças infecciosas ${ }^{36} \mathrm{e}$ alterando o funcionamento dos órgãos reprodutores com consequências para a fertilidade ${ }^{37,38}$.

Outro ponto fundamental éo modelo de produção agrícola, baseado no agronegócio demonocultura em larga escala, dependente do uso de agrotóxicos, com seus impactos extremamente danosos à saúde e ao meio ambiente, levando à contaminação do ar, da água e do solo, e às enfermidades emortes. I sto requer legislações quepossam exercer um controle mais rigoroso durante todo ciclo de vida da produção e da utilização de agrotóxicos e de todos seus resíduos, comprometendo o conjunto dos atores sociais, desde a indústria química e suas revendas até os produtores e trabalhadores rurais com uma gestão integrada e ambientalmente mais segura e saudável.

Nesta perspectiva, os governos dos países da América do N ortee Europa Ocidental estão promovendo a regulamentação para a redução do nível de utilização destes produtos químicos utilizados na agricultura, estimulando a chamada agricultura biológica, método que se caracteriza pela rotação de cultura, usos restritos de pesticidas e fertilizantes, entre outras ${ }^{39}$. Paradoxalmente, em 2008, o Brasil assumiu o posto de maior consumidor de agrotóxicos do mundo, superando os Estados Unidos. Agrotóxicos proibidos na
União Europeia, Estados Unidos, Canadá, Japão e China continuam sendo utilizados no Brasil ${ }^{40}$.

O Ministério da Saúde instituiu Grupo de Trabalho ${ }^{41}$ em caráter permanente, para elaborar e acompanhar a implementação do Plano Integrado de ações de vigi lância em saúde relacionada a riscos e agravos provocados por agrotóxicos, tendo sido elaborado um modelo de Vigilância e Atenção Integral à população Exposta aos Agrotóxicos.

Impactos do complexo produtivo da saúde sobre o ambiente

Outra dimensão da saúde na economia verde diz respeito ao impacto de suas cadeias produtivas no ambiente, seja na produção de resíduos, nas formas de organização do trabal ho ou na eficácia da atenção e vigilância em saúde. 0 setor saúde, especialmente quando adota um modelo universal, desempenha importante papel como indutor do crescimento econômico e da competitividade. No Brasil, éresponsável por boa parte dos investimentos em pesquisa e desenvolvimento, apresentando forte impacto sobre 0 estágio de desenvolvimento nacional. Porém, os interesses predominantes se movem pela lógica econômica do lucro e não para o atendimento das necessidades da saúde ${ }^{42}$.

A indústria bioquímica e farmacêutica gera efluentes com composição e quantidade muito variadas devido ao grande número de fármacos existentes, mais a introdução de novos e a sazonalidade das produções. Os riscos ambientais decorrentes de resíduos químico-farmacêuticos estão relacionados com os despejos industriais ou laboratoriais inadequados, assim como com o descarte aleatório de medicamentos vencidos ou sobras, feito por grande parte das pessoas no lixo comum ou na rede pública de esgoto. Estes resíduos podem trazer como consequências a contaminação da água, do solo e deanimais, além do risco direto à saúde de pessoas que possam reutilizá-los por acidente ou mesmo intencionalmente, levando ao surgimento de reações adversas graves, intoxicações, entre outros problemas.

Os efluentes líquidos dos serviços de saúde também possuem características peculiares que merecem atenção diferencial. 0 uso de antibióticos promovea seleção de bactérias multirresistentes ede genes de resistência a antibióticos. As estações de tratamento de efluente líquido de serviços de saúde são inexistentes na maioria das vezes.

Em termos de tecnologias de tratamentos de água e esgoto, a utilizaçao de carvão ativado granular, a ozonização e processos de oxidação são 
eficientes para remoção de até $80 \%$ desses contaminantes. No entanto, são tecnologias ainda caras e pouco usuais no Brasil. Incentivosnessaárea tecnológica seriam importantes a fim de desenvolver métodos com boa relação-custo benefício eque protegesse a população eo ambiente contra a exposição contínua desses contaminantes.

Os resíduos dos serviços de saúde (RSS) re presentam um potencial de risco em duas situações: para a saúde ocupacional de quem manipula essetipo de resíduo; e, para o meio ambiente e a população, como decorrência da destinação inadequada de qualquer tipo de resíduo, alterando as características do meio ${ }^{43}$.

Os RSS também podem favorecer o transporte de organismos multirresistentes dos estabel ecimentos de saúde para 0 ambiente ${ }^{44}$. Os rejeitos radioativos ou contaminados com radionuclídeos provenientes de laboratórios de análises clínicas, serviços de medicina nuclear e radioterapia, devem seguir as normas da Comissão Nacional de Energia Nuclear ${ }^{45}$. No Brasil, cerca de $56 \%$ dos municípios brasileiros dispõem de forma inadequada seus resíduos sólidos hospitalares, sendo que $30 \%$ deste total correspondem aos lixões. 0 restante os deposita em aterros controlados, sanitários e aterros especiais ${ }^{43}$. A disposição desses resíduos em locais inadequados permite que 0 chorume e todos os agentes patogênicos se infiltrem no solo, contaminando-o e comprometendo os lençóis freáticos, além de ampliar os riscos aos catadores. Também há o risco de contaminação do ar, dada quando os resíduos são tratados pelo processo de incineração descontrolado ${ }^{43}$.

Com relação às formas de tratamento adotadas pelos municípios, cerca de $20 \%$ dos municípios realizam a queima a céu aberto (cerca de $20 \%$ ), $11 \%$ incineram e $22 \%$ não tratam de forma alguma seus resíduos ${ }^{43}$.

Existem regras para o descarte dos Resíduos de Serviços de Saúde, as quais estão dispostas na Resolução n 306 de dezembro de 2004, da Anvisa. Entre elas, uma estabelece que a segregação, 0 tratamento, 0 acondicionamento e 0 transporte adequado dos resíduos são de responsabilidade de cada unidade de saúde onde foram gerados, compromisso este que é sacramentado pela elaboração obrigatória do Plano de Gerenciamento de Resíduos de Serviços de Saúde (PGRSS) por parte dos estabelecimentos geradores. A Lei $n-$ 12.305/10, queinstitui a Política Nacional de Resíduos Sólidos (PNRS), regulamenta a eliminação de lixões e a consequente disposição final ambientalmente adequada dos rejeitos até 2014.

Um dos entraves atuais para o gerenciamento adequado destes resíduos está nafiscalização. Den- tro do estabelecimento de saúde os responsáveis pela fiscalização são os órgãos de Vigilância Sanitária e, após sua saída (transporte e disposição final) é de responsabilidade do órgão ambiental. A falta de integração entre esses dois órgãos torna a fiscalização deficiente. Dessa forma, énecessário que se implementeuma política nacional para gerenciamento dos RSS, integrada entre o M S e M M A, assim como ações delogística einfraestrutura local para coleta, transporteetratamento dos mesmos. Seu tratamento protege a saúde da população e consequentemente otimiza o processo de reciclagem. Deve-seinvestir também em infraestrutura e serviços, como empresas de transporte adequado, empresas para tratamento, reciclagem ereaproveitamento de metais e outros materiais, sistema de logística reversa, entre outros.

Como dito anteriormente, o complexo produtivo da saúde tem papel decisivo, pois constitui um campo em queinovação tecnológica eacumulação de capital geram oportunidades de investimento, trabalho e renda, além de produzir avanços importantes para melhorar o estado de saúde das pessoas ${ }^{46}$. Entretanto, 0 seu modelo de organização é hegemonicamente o da economia marrom, tornando-se necessário projetar estratégias de mudança para uma economia sustentável. Um ambiente equilibrado promove a saúde, bem fundamental para o desenvolvimento econômico de um país. Essa é uma das justificativas para mudança do modelo econômico para uma economia verde.

Por exemplo, estratégias de construção de serviços de saúde "verdes" são uma oportunidade de engajamento do setor no processo de transição para a economia sustentável. Abrangem cinco áreas principais: planejamento do local, consumo de energia, de água e de materiais e a qualidade do ambiente interno. 0 projeto deve garantir a sustentabilidade destes fatores e a sua interação. Um edifício “verde" permite a redução de custos entre $15 \%$ e $25 \%$ de energia e água, de $70 \%$ da emissão de óxido nitroso, de $50 \%$ da emissão de gás carbônico e de $20 \%$ de combustível para o aquecimento de água, o que torna o investimento nestetipo de construção importante não apenas do ponto de vista da sustentabilidade ecológica como da eficiência econômica ${ }^{47}$.

Lógica produtiva tradicional versus novas racionalidades

A principal crítica à Economia Verde é a sua aplicabilidade concreta. Com efeito, de modo antagônico aosorganismos internacionaise "major groups", atores distintos sustentam que 0 conceito e suas práticas significam um aggiorna- 
mento do capitalismo, sustentado pelo interesse dos conglomerados econômicos transnacionais, das grandes corporações e de seus aliados nos governos, focalizando sua argumentação na utilização de tecnologias de ponta como solução para os efeitos da economia marrom, evitando discutir sua raiz, representada pelas formas de organização social e econômica capitalistas.

Com efeito, éinegável queo queestá em disputa são projetos alternativos de sociedade, defendidos por atores ideologicamente distintos e em muitos casos radicalmente antagônicos. A forma como o modo de produção capitalista se reproduziu, passou a ameaçar a própria possibilidade de sua reprodução, tanto pelo consumo dos serviços ecossistêmicos, quanto pela perda de legitimidade social do sistema, contexto semelhanteao queocorreu no período inicial darevolução industrial, quando as péssimas condições laborais da classe operária passaram a dizimar sua força de trabalho.

A resposta naquele momento foi a ampliação dos direitos trabalhistas e sociais nos países de senvolvidos, seguida pela progressiva descentralização dos processos produtivos mais penosos e/ou degradadores do meio ambiente para colônias, países pobres e em desenvolvimento, onde a capacidade de organização dos trabalhadores era menor, assim como os custos de produção.

Ainda que atualizando o modo de produção capitalista, este momento abriu a possibilidade de construção dos estados de Bem-estar Social e a ampliação dos direitos políticos, rompendo com a perspectiva liberal então dominante do Estado mínimo, permitindo a regulação do mercado por meio de políticas públicas. I sso não foi suficiente, entretanto, para reverter o quadro de assimetria e de dominação social, cuja legitimidade se deslocou da esfera da interação para a da técnica.

Esteenfrentamento entre projetoséinerenteà história da humanidade e, em estados disnômicos do sistema, demandam respostas para um novo equilíbrio que podese dar tanto pela atualização do projeto do capital quanto por iniciativas mais emancipatórias e solidárias. N esse espaço são necessárias proposições mais afirmativas dos atores que defendem uma sociedade mais autônoma e com justiça socioambiental, não devendo se limitar a protestos numa cúpula oposta. É preciso "traçar uma estratégia demudança, com perspectivas claras e fortes, organizadas em volta de um reduzido número de grandes mudanças que tenham sido identificadas coletivamente" ${ }^{\prime 4}$.

Aqueles que defendem a tese do "esverdeamento do capitalismo" argumentam que a economia verde não enfrenta a questão do modelo de desenvolvimento, apenas propõe adequações ao existente para torná-lo "sustentável", sem mudanças estruturais. As tecnologias verdes seriam controladas pelas corporações internacionais com a perspectiva de obtenção de lucro, por meio do seu comércio, caso venham a ser adotadas como solução para redução das emissões.

Para aqueles que advogam essa análise, isto "simboliza certa submissão dos Estados nacionais ao capital do setor privado, movimento iniciado justamente a partir dos O bjetivos do M ilê nio, no início dos anos 2000, quando a ONU se dobrou ao poder do capital e passou a atuar a partir de diretrizes ditadas pelos interesses dos países mais ricos e das instituições do sistema financeiro e do comércio mundial"2.

Outros avaliam que a ausência de uma definição consensual de'economia verde' no processo da Rio+20 éum artifício para a atualização do projeto do capital. $\mathrm{Na}$ ausência de fortes políticas sociais e de novas estruturas de governança, as mesmas companhias [...] transnacionais que controlam a nossa economia atual irão permanecer no controle de qualquer economia que possa haver no nosso futuro - seja qual for a sua cor ${ }^{49}$.

No momento atual, as tecnologias estão sendo apontadas como uma alternativa para sanar os problemas climáticos e resolver, consequentemente, as questões sociais, especialmente em relação à fome e à distribuição de alimentos. Dentre elas, destacam-se a nanotecnologia, a Geoengenharia, a Robótica, a Biotecnologia, entre outras $^{50}$. Dessa forma, a fome pode ser saciada com a biotecnologia, a geoengenharia éa solução para o aquecimento global, a biologia sintética para a substituição do petróleo e a transformação da biomassa. "M eio século depois do nascimento do movimento ambiental moderno, todos os problemas sociais parecem exigir não políticas, mas sim soluções tecnológicas" 49 .

Entretanto, não se pode atribuir a elas a solução para problemas que são resultados do modelo politicamente definido de desenvolvimento econômico. 0 modo de produção capitalista e o processo de desenvolvimento econômico pósindustrial, ainda que baseiem sua legitimidade no desenvolvimento da técnica eda ciência, conseguiu legitimar-se principalmente pelas formas de organização social que produziu e que de modo geral não permitiu a expansão da autonomia agravando as iniquidades, as assimetrias sociais e os processos de exploração.

Desafios da Agenda da Sustentabilidade e Saúde

A saúdeé histórica e socialmente construída, o que caracteriza sua determinação social. 0 ob- 
jeto da saúde é a vida. A vida está ameaçada pelo atual modo de produção e consumo. A sustentabilidade é a ponte dialógica entre a saúde, 0 ambiente e a economia, representada pela possibilidade do desenvolvimento sustentável.

Ainda que se aponte para a inviabilidade da vida no planeta se houver a continuidade do modelo hegemônico de produção, este continua a reproduzir-se e a exponenciar suas consequências. Por outro lado, experiências de organização econômica e social mais solidárias e eficientes se ampliam, gerando aprendizados e alternativas 5,10,14,51.

Tanto as propostas de políticas, programas e projetos, quanto a literatura especializada destacam o território como categoria central. Com efeito, toda investigação ou formulação parte de um território vivo, de uma territorialidade, entendida como o conjunto devalores e de práticas referidos a determinado espaço e em determinado tempo e que caracterizam a sua produção social, que se dá a partir e sobre uma realidade particular onde os vetores da racionalidade dominante entram em embatecom a emergência de outras formas de vida, o queexigeprojetos eações que sejam capazes de compreender e - consequentemente - de transformar as práticas sociais referidas a territórios, produzindo autonomia individual e coletiva ${ }^{52-57}$.

Ora, não existe "intervenção no mundo" anistórica, isolada de um determinado contexto, determinado espaço e tempo, determinados sujeitos. Portanto, a possibilidade teórico-prática do sustentável e do saudável só existe referida aos territórios eterritorialidades específicas.

Porém, para além disto, a definição mesmo do queé sustentável e saudável também só é possível "em situação", a partir do diálogo entre sujeitos, suas experiências e interesses, da "ecologia de saberes" como propõe Santos ${ }^{57}$.

Para a Agenda do desenvolvimento sustentável, portanto, intervir sobre as distintas dimensões da determinação social da saúde, articulando diferentes escalas e integrando-se às agendas de economia solidária, gestão euso do território, agroecologia, segurança al imentar, resgate e atualização cultural, entreoutras, éfundamental para que se torne promotora de equidade e sustentabilidade. Seus focos de ação devem ser intersetoriais, esuas estratégias devem dar "preferência às formas de conhecimento que garantam a maior participação dos grupos sociais envolvidos na concepção, na execução, no controlee na fruição da interven ção" 57 .

N ovos olhares sobre a saúde e a doença significam: "compartir da certeza de que a humanidade vive em um período de responsabilidade planetária, que coloca a luta pela vida como preocupação central" e "subverter radicalmente a concepção hegemônica sobre o conceito de saúde no âmbito da saúde coletiva" ${ }^{28}$.

I sto não significa, entretanto, que as alternativas propostas para sua atualização, em especial as oriundas das instituições tradicionais escapem à lógica hegemônica do conhecimento científico ocidental, conformando-se muitas vezes como conservadoras, ou "abissais" na expressão de Santos ${ }^{57}$.

0 conceito, portanto, mais que apontar para uma situação-objetivo, precisa se pautar pelo empoderamento e produção de autonomia, equidade e sustentabilidade, buscando construir cartografias epistemológicas contra-hegemônicas derivadas do cotidiano reinventado criticamente ${ }^{59}$.

Territórios sustentáveis são a configuração do Cotidiano da H istória após sua apropriação crítica pelos sujeitos a partir da ecologia de saberes e por meio de uma pedagogia da autonomia, resultando em governança local solidária, produção sustentável epolíticas efetivas de cidadania ${ }^{53,57,59,60}$.

A Rio+20 abrea possibilidade de se definir o conceito de economia verde e uma agenda de implantação de um novo modelo de produção e organização social que promova a justiça socioambiental, incentivando a participação social e as formas de governança, permitindo a ausculta dos movimentos sociais, comunidades tradicionais, governos, empresários, organizações sociais e cientistas na definição de uma agenda concreta de implementação de ODS e de mecanismos de governança capazes de implementá-los, especialmente em nível local.

\section{Colaboradores}

E Gallo trabalhou na concepção teórica, elaboração e redação final do texto; AFF Setti e DP $M$ agalhães trabalharam no levantamento bibliográfico, elaboração e redação final do texto; DF Buss, FA Franco N etto e JM H M achado realizaram a revisão crítica do trabal ho e a elaboração do texto; PM Buss realizou a coordenação do grupo, a concepção teórica, a revisão crítica do trabalho e aprovou a versão final do texto para publicação. 
1. Belinky A. U ma economia democrática para o desenvolvimento sustentável. 2012. [acessado 2012 abr 17]. Disponível em: http://rio20.net/pt-br/documentos/umaeconomia-democratica-para-0-desenvolvimentosustentavel

2. Pietrovsky I. Por trás do documento que pautará a Rio+20 oficial. 2012. [acessado 2012 abr 17]. Disponível em: http://rio20.net/pt-br/documentos/portras-do-documento-que-pautara-a-rio20-oficial

3. Club of Rome. The limits to growth. 1972 [acessado 2012 abr 17]. Disponível em: http://www.clubofrome. at

4. Comisión Mundial del Medio Ambiente y del Desarroll (CMMAD). Nuestro futuro común. Madri Alianza Editorial; 1987.

5. Drexhage J, Murphy D. Sustainable Development: From Brundtland to Rio 2012. Background Paper prepared for consideration by the High Level Panel on Global Sustainability at its first meeting. New York: United Nations Headquarters; 2010.

6. The Lancet. Global health in 2012: development to sustainability. The Lancet 2012; 379(9812):193.

7. Gallo E, Setti AFF. Abordagens Ecossistêmica e Comunicativa na Implantação de Agendas Territorializadas de Desenvolvimento Sustentável e Promoção da Saúde. Cien Saude Colet. No prelo 2012.

8. Feola G, Bazzani R, organizadores. Desafíos y estrategias para la implementación de un enfoque ecossistémico para la salud humana en los países em desarollo - reflexiones a propósito de las consultas regionales. M ontevideo: CIID; 2002.

9. Setti AFF, Gallo E. Desenvolvimento Sustentável e Promoção da Saúde: proposta de Matriz de Avaliação Qualitativa de Projetos Locais. Saúde em Debate 2009; 33(83):407-419.

10. Franco Netto G. M eio ambiente, saúde e desenvolvimento sustentável. Cien Saude Colet 2009; 14(6):1972-1982.

11. Organização Pan-Americana de Saúde (OPAS). Enfoques ecossistêmicos em saúde - perspectivas para sua adoção no Brasil e países da América Latina. Organização Pan-Americana da Saúde. Brasília: OPAS; 2009.

12. Caldas A, Quintana S. Esverdeando o Capitalismo: a farsa das corporações para a Rio+20. Sustentabilidade e Desenvolvimento. Le monde Diplomatique Brasil 2011; 5(53):16-17.

13. Fundo M undial para a Natureza (WWF-Brasil). Planeta Vivo. Relatório 2010: Biodiversidade, biocapacidade e desenvolvimento. Suíça: WWF; 2010.

14. Programa das $\mathrm{N}$ ações Unidas para o M eio Ambiente (PNUMA). Rumo a uma economia verde: caminhos para o desenvolvimento sustentável e a erradicação da pobreza. 2011 [acessado 2001 fev 23]. Disponível em: http://www.unep.org/greeneconomy

15. Organização para a Cooperação e Desenvolvimento Económico (OCDE). Towards green growth: $A$ summary for policy makers. OECD M eeting of the Council at Ministerial Level. Paris: OECD; 2011.

16. Stern N. Stern Review: The Economics of Climate Change; 2006
17. UN. The Millennium Development Goals Report 2011. [acessado 2012 abr 19] Disponível em: http:// www.un.org/millenniumgoals/11_M DG\%20Report_ EN.pdf

18. CEPAL. Panorama Social de América Latina, 2008. [acessado em 2012 abr 19] Disponível em: http://www. eclac.cl/cgi-bin/getProd.asp?xml=/publicaciones/ $\mathrm{xml} / 2 / 34732 / \mathrm{P} 34732 . x m|\& x s|=/ d d s / t p l / p 9 f . x s \mid$

19. European Community. The economics of ecosystems and biodiversity (TEEB). Germany: Welzel + Hardt; 2008.

20. Organização das Nações Unidas (ONU). Objectivos de desarollo del milênio. Informe de 2011. N ova Iorque: ONU; 2011.

21. Instituto de Pesquisa Econômica Aplicada (IPEA). Objetivos de Desenvolvimento do M ilênio: relatório de acompanhamento. Brasilia: IPEA; 2010.

22. Brasil. Apresentação do Plano Brasil sem Miséria. [acessado 2012 fev 04]. Disponível em: http:// www.brasilsemmiseria.gov.br/apresentacao-2/

23. Brasil. Lei $n-12.512$ de 14 de outubro de 2011 . Institui o Programa de Apoio à Conservação Ambiental e o Programa de Fomento às Atividades Produtivas Rurais. Diário Oficial da U nião 2011; 17 out.

24. M illennium Ecosystem Assessment. Ecosystems and Human Well-being: Biodiversity Synthesis. World Resources Institute. Washington: DC; 2005.

25. Comissão Nacional Sobre Determinantes Sociais Da Saúde (CNDSS). As Causas Sociais das Iniqüidades em Saúde no Brasil - Relatório Final. 2008 [acessado 2011 mar 3]. Disponível em: http://www.cndss. fiocruz.br/pdf/home/relatorio.pdf.

26. Organização Pan-Americana De Saúde (OPAS). He alth in the Americas. Scientific Publication. Washington: Pan American Health Organization; 2007. ${ }^{\circ}$ 622.

27. Rodríguez-M orales AJ. Ecoepidemiología y Epidemiología Satelital: Nuevas Herramientas en el Manejo de Problemas en Salud Pública. Rev Per M ed Exper y Salud Pública 2005; 22(1):54-63.

28. World Health Organization (WHO). Climate change and human health - risks and responses. Geneve: WHO; 2003.

29. Intergovernmental Panel on Climate Change (IPCC). Climate Change 2007: Impacts, Adaptation, and Vulnerability.Contribution of Working Group II to the Fourth Assessment Report of the Intergovernmental Panel on Climate Change. In: Parry ML, Canziani O, Palutikof J, Linden PVD, Hanson $\mathrm{H}$, organizadores. United Kingdom: Cambridge University Press; 2007.

30. Mills DM. Climate change, extreme weather events, and us health impacts: what can we say? J 0 ccup Environ Med 2009; 51(1):26-32

31. Organização Pan-Americana De Saúde (OPAS). Climate Change and Disaster Programs in the $\mathrm{H}$ ealth Sector. Disasters: Preparedness and M itigation in the Americas. Washington: OPAS; 2008. v. 110.

32. Ostfeld RS, Keesing F. The function of biodiversity in the ecology of vector-borne zoonotic diseases. Can J Zool 2000; 78:2061-2078. 
33. Southgate VR et al. Studies on the biology of schistosomiasis with emphasis on the Senegal River basin. M em Inst Oswaldo Cruz 2001; 96(Supl):75-78.

34. Zheng J, Gu XG, Xu YL, Ge JH, Yang XX, $\mathrm{He} \mathrm{CH}$, Tang $C$, Cai KP, Jiang QW, Liang YS, Wang TP, Xu XJ, Zhong JH, Yuan HC, Zhou XN.. Relationships between the transmission of Schistosomiasis japonica and the construction of the Three Gorge Reservoir. Acta Trop 2002; 82(2):147-156.

35. World Health Organization (WHO). Health Co-Benefits of Climate Change Mitigation. Geneve: WHO; 2011.

36. Penteado JCP, Vaz JM . O legado das bifenilas policloradas (PCB). Quím N ova 2001; 24(3):390-398.

37. Patnaik P. Guia geral: propriedades nocivas das substâncias químicas. Belo Horizonte: Ergo; 2002.

38. Wozniak AL, Bulayeva NN, Watson CS. Xenoestrogens at Picomolar to Nanomolar Concentrations Trigger Membrane Estrogen Receptor-alpha-M ediated $\mathrm{Ca}++$ Fluxes and Prolactin Release in $\mathrm{GH} 3 /$ B6 Pituitary Tumor Cells. Environ Health Perspect 2005; 113(4):431-439.

39. Regulamento (CE) N. ${ }^{\circ} 404 / 2008$ de 6 de Maio de 2008. Altera 0 anexo II do Regulamento (CEE) n. 0 2092/91 do Conselho relativo ao modo de produção biológico de produtos agrícolas no que se refere à autorização de spinosade, bicarbonato de potássio e octanoato de cobre e à utilização de etile no. Jornal Oficial da União Européia; 2008; 7 maio; p. 8-10. [acessado 2012 fev.10]. Disponível em: http:/ /eur-lex.europa.eu/LexU riServ/LexUriServ.do?uri= CELEX:32008R0404:PT:HTM L

40. Agência Nacional de Vigilância Sanitária (ANVISA). Reavaliação de agrotóxicos: 10 anos de proteção a população. 2009. [acessado 2012 fev 07]. Disponível em: http://www.anvisa.gov.br/divulga/noticias/2009 1020409.htm

41. Portaria SE/M S No 397, de 9 de outubro de 2007.Constitui Grupo de Trabalho, no âmbito do Ministério da Saúde, em caráter permanente, para elaborar e acompanhar a implementação do Plano Integrado de ações de vigilância em saúde relacionada a riscos e agravos provocados por agrotóxicos e de medidas preventivas e de controle do uso de agrotóxicos visando à proteção à saúde humana e dá outras providências. Diário Oficial da União 2007; 9 Out.

42. Gadelha CAG. Desenvolvimento, complexo industrial da saúde e política industrial. Rev Saude Publica 2006; 40(n. Esp.):11-23.

43. Agência Nacional de Vigilância Sanitária (AN VISA). M anual de gerenciamento de resíduos de serviços de saúde. Brasília: M inistério da Saúde; 2006.

44. World $\mathrm{H}$ ealth Organization (WHO). Wastes from health-care activities. 2007. [acessado 2011 ago 02]. Disponível em: http://www.healthcarewaste.org/en/ 115 overview.html

45. Comissão Nacional de Energia Nuclear (CNEN). M anual CNEN-NE-6.05 - Gerência de Rejeitos Radioativos em Instalações Radiativas. Resolução CNEN 19/85. Regulamenta os serviços de medicina nuclear. Diário Oficial da União 1985; 17 Dez.
46. Gadelha CAG. 0 complexo industrial da saúde e a necessidade de um enfoque dinâmico na economia da saúde. Cien Saude Colet 2003; 2(8):521-535.

47. Sociedade Beneficente Israelita Brasileira Albert Einstein (SBIBAE). Certificação Edifício Verde. [acessado 2012 jan 23]. Disponível em: http://www. einstein.br/sobre-a-sociedade/sustentabilidade/ certificacao-edificio-verde/Paginas/certificacaoedificio-verde.aspx

48. Portal RIO +20. (site na Internet] [acessado 2011 dez 03]. Disponível em: http://www.rio20.gov.br/

49. Wetter KJ. Rio+20: os equívocos da economia verde e das tecnologias. 2012. [acessado 2012 abr 17]. Disponível em: http://www.yhu.unisinos.br/entrevistas/ 505705-rio20-os-equivocos-da-economia-verde-edas-tecnologias-entrevista-especial-com-kathy-jowetter.

50. ETC Group. Tackling Technology: three proposals for Rio contribution to the Rio+20 zero draft. 2011. [acessado 2012 fev 06]. Disponível em: http://www. etcgroup.org/en/node/5290

51. United Nations Conference on Trade and Development (UNCTAD). The Road to Rio+20 - For a development-led green economy. New York, Geneva: UNCTAD; 2011.

52. Akerman $M, M$ endes $R$, Bógus $C M$, Westphal $M F$, Bichir A, Pedroso ML. Avaliação em promoção da saúde: foco no "município saudável". Rev Saude Publica 2002; 36(5):638-646

53. Freire P. Pedagogia da autonomia: saberes necessários à prática educativa. São Paulo: Paz e Terra; 2003.

54. Santos M. Por uma outra globalização: do pensamento único à consciência universal. $10^{\underline{a}}$ ed. Rio de Janeiro: Record; 2003.

55. Gallo E, Freitas LE, Reis R. Flexibilidade, Responsabilização e Autonomia: o caso da Diretoria de Investimentos e Projetos Estratégicos do M inistério da Saúde (DIPE - MS). Saúde em Debate 2006; 30:58-79.

56. Gallo E. Gestão Pública e Inovação. Tecnologias de Gestão e a Reinvenção do Cotidiano Organizacional [tese]. Rio de Janeiro: Escola Nacional de Saúde Pública Sérgio Arouca; 2009.

57. Santos BS. Epistemologias do Sul. São Paulo: Cortez; 2010.

58. Gallo E. Crise teórica e crise política - impactos na saúde coletiva. In: Fleury $S$, organizadora. Saúde: coletiva? Questionando a onipotência do social. Rio de Janeiro: Relume-Dumará; 1992.

59. Gallo E. Alienação, Inovação e Cotidiano Organizacional: Teses e Hipóteses. In: Mandarino ACS, Gomberg E, organizadores. Leituras de Novas Tecnologias e Saúde. Salvador: EDUFBA; 2009.

60. Heller A. O Cotidiano e a História. 8a Ed. São Paulo: Paz e Terra; 2008.

Artigo aprovado em 01/04/2012

Apresentado em 21/04/2012

Versão final apresentada em 04/04/2012 